\title{
Molecular basis of Rrn3-regulated RNA polymerase I initiation and cell growth
}

\author{
Claudia Blattner, ${ }^{1}$ Stefan Jennebach, ${ }^{1}$ Franz Herzog, ${ }^{2}$ Andreas Mayer, ${ }^{1}$ Alan C.M. Cheung, ${ }^{1}$ \\ Gregor Witte, ${ }^{1}$ Kristina Lorenzen, ${ }^{3}$ Karl-Peter Hopfner, ${ }^{1}$ Albert J.R. Heck, ${ }^{3}$ Ruedi Aebersold, ${ }^{2,4}$ \\ and Patrick Cramer ${ }^{1,5}$ \\ ${ }^{1}$ Gene Center, Department of Biochemistry, Center for Integrated Protein Science Munich (CIPSM), Ludwig-Maximilians- \\ Universität München, 81377 Munich, Germany; ${ }^{2}$ Department of Biology, Institute of Molecular Systems Biology, Eidgenössiche \\ Technische Hochschule (ETH) Zurich, 8093 Zurich, Switzerland; ${ }^{3}$ Biomolecular Mass Spectrometry and Proteomics Group, \\ Bijvoet Center for Biomolecular Research, Utrecht Institute for Pharmaceutical Sciences, University of Utrecht, $3584 \mathrm{CH}$ \\ Utrecht, The Netherlands; ${ }^{4}$ Faculty of Science, University of Zurich, 8057 Zurich, Switzerland
}

Cell growth is regulated during RNA polymerase (Pol) I transcription initiation by the conserved factor Rrn3/TIFIA in yeast/humans. Here we provide a structure-function analysis of Rrn3 based on a combination of structural biology with in vivo and in vitro functional assays. The Rrn3 crystal structure reveals a unique HEAT repeat fold and a surface serine patch. Phosphorylation of this patch represses human Pol I transcription, and a phosphomimetic patch mutation prevents Rrn3 binding to Pol I in vitro and reduces cell growth and Pol I gene occupancy in vivo. Cross-linking indicates that Rrn3 binds Pol I between its subcomplexes, AC40/19 and A14/43, which faces the serine patch. The corresponding region of Pol II binds the Mediator head that cooperates with transcription factor (TF) IIB. Consistent with this, the Rrn3-binding factor Rrn7 is predicted to be a TFIIB homolog. This reveals the molecular basis of Rrn3-regulated Pol I initiation and cell growth, and indicates a general architecture of eukaryotic transcription initiation complexes.

[Keywords: Gene transcription; rRNA production; ribosome biogenesis; promoter specificity; gene class-specific RNA synthesis]

Received July 4, 2011; revised version accepted August 24, 2011.

Gene transcription in eukaryotic cells is performed by related RNA polymerases (Pols). Pol I produces the 35S rRNA precursor, Pol II synthesizes mainly mRNAs, and Pol III makes small noncoding RNAs such as tRNAs. The structure of Pol II and models of the cores of Pol I and Pol III are available (Jasiak et al. 2006; Kuhn et al. 2007; Cramer et al. 2008). All three polymerases require the TATA-box-binding protein (TBP) for initiation. Pol II initiation further requires transcription factor (TF) IIB, which bridges TBP and Pol II (Kostrewa et al. 2009; Liu et al. 2010). A TFIIB homolog is needed for Pol III initiation (Wang and Roeder 1995; Teichmann et al. 2000), but no TFIIB homolog was reported in the Pol I system.

During Pol I initiation in yeast, TBP assembles at the rDNA promoter with the core factor, which comprises subunits Rrn6, Rrn7, and Rrn11, and the upstream activating factor (Keener et al. 1998; Bordi et al. 2001; Moss et al. 2007). Initiation additionally requires the essential Pol I-specific factor Rrn3, or TIF-IA in humans (Yamamoto et al. 1996; Bodem et al. 2000; Moorefield et al. 2000),

${ }^{5}$ Corresponding author.

E-mail cramer@genzentrum.lmu.de.

Article published online ahead of print. Article and publication date are online at http://www.genesdev.org/cgi/doi/10.1101/gad.17363311. which binds the Pol I subunit A43 (Milkereit and Tschochner 1998; Peyroche et al. 2000; Cavanaugh et al. 2008). The interaction of Rrn3 with the Pol I complex is regulated by growth factor signaling pathways that connect nutrient availability to rRNA production (Drygin et al. 2010; Grummt and Voit 2010), which can account for up to $60 \%$ of all nuclear transcription (Warner 1999). Signaling cascades trigger phosphorylation and dephosphorylation of Pol I and Rrn3 (Fath et al. 2001; Cavanaugh et al. 2002; Claypool et al. 2004; Panova et al. 2006; Gerber et al. 2008; Hoppe et al. 2009; Drygin et al. 2010). Unphosphorylated Rrn3/TIF-IA binds Pol I, whereas certain phosphorylations of TIF-IA prevent Pol I binding and down-regulate transcription (Mayer et al. 2004, 2005).

To understand how Pol I transcription and cell growth are regulated by Rrn3, structural insights into the Pol IRrn3 initiation complex are required. Whereas models for the minimal initiation complexes of Pol II and Pol III were described (Chen and Hahn 2004; Kostrewa et al. 2009; Liu et al. 2010; Vannini et al. 2010), the architecture of the Pol I initiation complex remains unknown. There are two reasons for this: the lack of a known TFIIB-related factor in the Pol I system, and the lack of information on the Rrn3 structure and its precise position on Pol I. Here we report the structure of full-length Rrn3 and provide ev- 
idence that Rrn7 is the TFIIB homolog in the Pol I system. We obtain cross-linking data for the Pol I-Rrn3 complex, functional data for a phospho-mimetic Rrn3 mutant, and a model for a minimal Rrn3-regulated Pol I initiation complex. These results indicate the molecular basis of cell growth regulation during Pol I transcription initiation and suggest that the Pol I-Rrn3 initiation complex is topologically related to the Pol II-Mediator initiation complex.

\section{Results}

\section{Rrn3 has a unique HEAT repeat structure}

We crystallized recombinant full-length Rrn3 from the yeast Saccharomyces cerevisiae (see the Materials and Methods). The structure was determined by multiwavelength anomalous diffraction with a mercury derivative and refined at $2.8 \AA$ r resolution (Table 1). The structure revealed 10 HEAT repeats $(\mathrm{H} 1-\mathrm{H} 10)$ formed by 20 anti-parallel $\alpha$ helices arranged in a superhelical fold (Fig. 1). Three additional C-terminal helices pack against repeats H6-H10. HEAT repeats are involved in protein-protein interactions and are found in transport proteins (Cingolani et al. 1999; Conti and Kuriyan 2000), but were not observed in TFs. The Rrn3 fold is conserved over species, since hydrophobic core residues are conserved between yeast and humans (Fig. 1A). The structure lacks only $47 \mathrm{~N}$-terminal residues, an acidic loop (residues D253-T322), loop $\alpha 20-\alpha 21$ (residues I555-
S574), and 10 C-terminal residues (Fig. 1A). These mobile, less conserved regions are apparently not required for essential Rrn3 functions in vivo, since deletion of the terminal tails or the acidic loop did not result in a growth phenotype in yeast (data not shown).

\section{Rrn3 forms a dimer in solution}

The asymmetric unit of the crystals contains a homodimer. The homodimer interface comprises polar and hydrophobic residues (orange in Fig. 1) and was predicted to be stable in solution (PISA) (http://www.ebi.ac.uk). To test this, we analyzed Rrn3 solutions by small-angle X-ray scattering (SAXS) (Fig. 2). SAXS revealed a radius of gyration of 4.4 $\mathrm{nm}$, which agrees with the calculated radius for the crystallographic dimer $(4.2 \mathrm{~nm})$, but not with the calculated monomer radius $(3.1 \mathrm{~nm})$. The scattering curve also agrees with a theoretical curve calculated from the dimer structure (Fig. 2A). Also, a SAXS-based ab initio model revealed a shape that resembles the dimer (Fig. 2B). To test whether dimerization in solution occurs as in the crystals, we mutated interface residues (Figs. 1, 2C). The Rrn3 variants D405A, R452G, and S444/S448D were purified and examined by size exclusion chromatography and static light scattering (Viscotec) (Fig. 2D). This revealed molecular weights (MWs) between 74 and $85 \mathrm{kDa}$, compared with $140-150 \mathrm{kDa}$ for the wild-type dimer (theoretical MW of $145 \mathrm{kDa}$ ). Thus, Rrn3 forms a stable homodimer in solution that resembles the dimer in the crystals.

Table 1. Diffraction data and refinement statistics

\begin{tabular}{|c|c|c|c|c|}
\hline \multirow[b]{2}{*}{ Crystal } & \multicolumn{3}{|c|}{ Mercury derivative } & \multirow[b]{2}{*}{ Native } \\
\hline & Peak & Inflection & Remote & \\
\hline \multicolumn{5}{|l|}{ Data collection } \\
\hline Space group & $\mathrm{P} 2_{1} 2_{1} 2_{1}$ & $\mathrm{P} 2_{1} 2_{1} 2_{1}$ & $\mathrm{P} 2{ }_{1} 2_{1} 2_{1}$ & $\mathrm{P} 2_{1} 2_{1} 2_{1}$ \\
\hline Unit cell axes & $94.8 \AA / 107.8 \AA / 160.7 \AA$ & $94.9 \AA / 108.2 \AA / 160.6 \AA$ & $94.8 \AA / 107.9 \AA / 161.1 \AA$ & $96.8 \AA / 101.8 \AA / 162.0 \AA$ \\
\hline Wavelength & $1.0086 \AA$ & $1.0094 \AA$ & $1.0129 \AA$ & $0.9814 \AA$ \\
\hline Resolution & $50-3.0 \AA(3.08-3.0 \AA)^{\mathrm{a}}$ & $50-3.0 \AA(3.08-3.0 \AA)$ & $50-3.0 \AA(3.08-3.0 \AA)$ & $50-2.85 \AA(2.92-2.85 \AA)$ \\
\hline Unique reflections & $63,653^{\mathrm{b}}(4723)$ & $63,104^{\mathrm{b}}(4650)$ & $63,345^{\mathrm{b}}(4706)$ & $38,054^{\mathrm{c}}(2784)$ \\
\hline Completeness & $100 \%(100 \%)$ & $99.7 \%(99.7 \%)$ & $99.7 \%(99.9 \%)$ & $99.9 \%(100 \%)$ \\
\hline Redundancy & 3.48 & 3.46 & 3.48 & 9.1 \\
\hline Mosaicity & $0.29^{\circ}$ & $0.25^{\circ}$ & $0.26^{\circ}$ & $0.28^{\circ}$ \\
\hline$R_{\mathrm{sym}}$ & $8.8 \%(56.3 \%)$ & $7.9 \%(46.2 \%)$ & $8.1 \%(56.3 \%)$ & $11.0 \%(65.6 \%)$ \\
\hline$<\mathrm{I} / \sigma \mathrm{I}>$ & $14.5(3.45)$ & $10.5(2.6)$ & $11.2(2.32)$ & $14.66(3.83)$ \\
\hline \multicolumn{5}{|l|}{ Refinement } \\
\hline Number of residues & & & & 953 \\
\hline $\begin{array}{l}\text { Number of } \\
\text { nonhydrogen atoms }\end{array}$ & & & & 8075 \\
\hline $\begin{array}{l}\text { Number of } \\
\text { solvent molecules }\end{array}$ & & & & 103 \\
\hline Average B-factor & & & & $62.5 \AA^{2}$ \\
\hline RMSD bonds & & & & $0.01 \AA$ \\
\hline RMSD angles & & & & $1.13^{\circ}$ \\
\hline$R_{\text {cryst }}$ & & & & $20.8 \%$ \\
\hline$R_{\text {free }}$ & & & & $24.2 \%$ \\
\hline $\begin{array}{l}\text { Preferred/allowed/ } \\
\text { disallowed }^{\mathrm{d}}\end{array}$ & & & & $96.9 \% / 3.1 \% / 0.0 \%$ \\
\hline
\end{tabular}

\footnotetext{
${ }^{a}$ Values in parentheses are for highest-resolution shell throughout.

${ }^{\mathrm{b}}$ Friedel pairs not merged.

${ }^{\mathrm{c}}$ Friedel pairs merged.

${ }^{\mathrm{d}}$ Ramachandran plot statistics from Molprobity.
} 


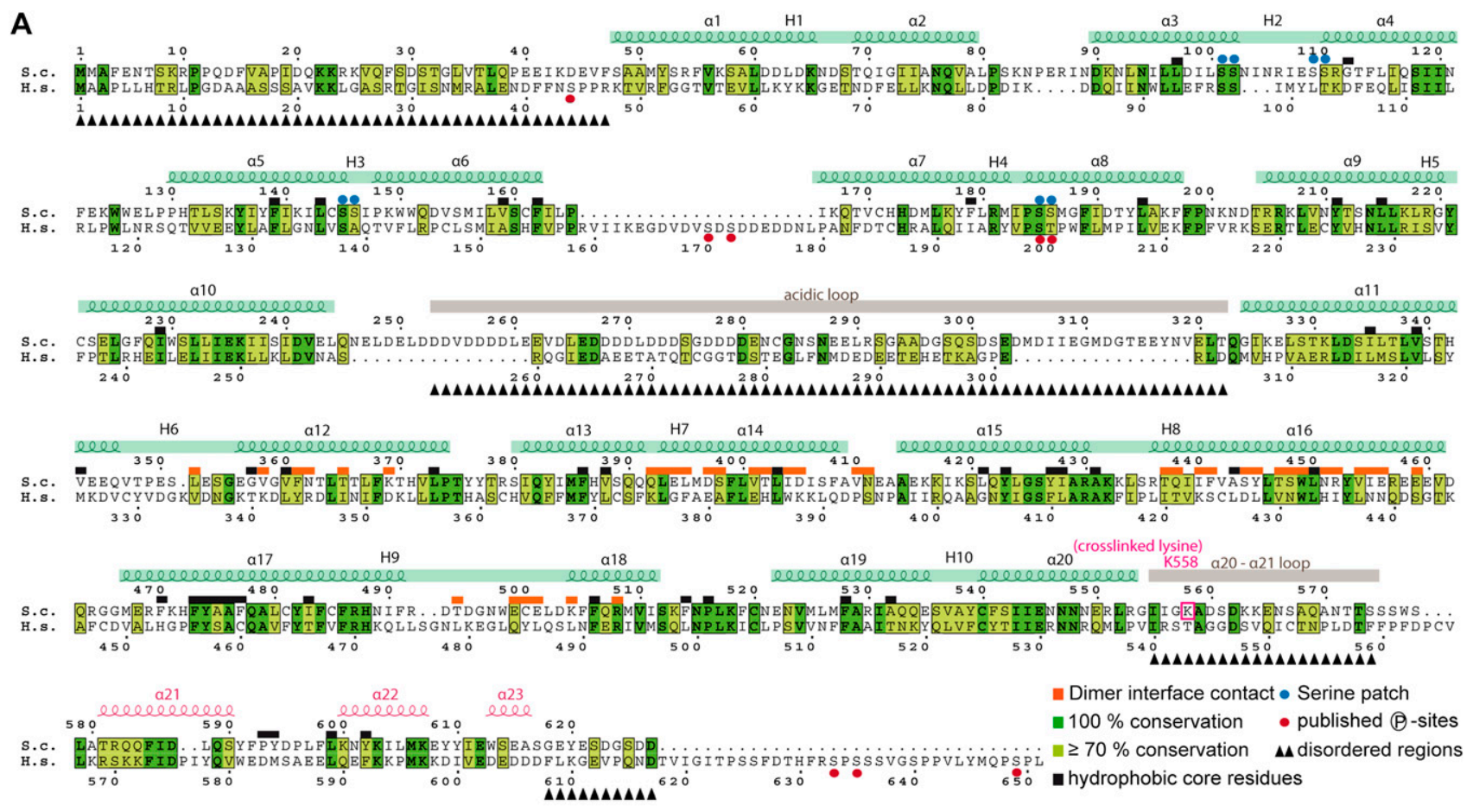

B

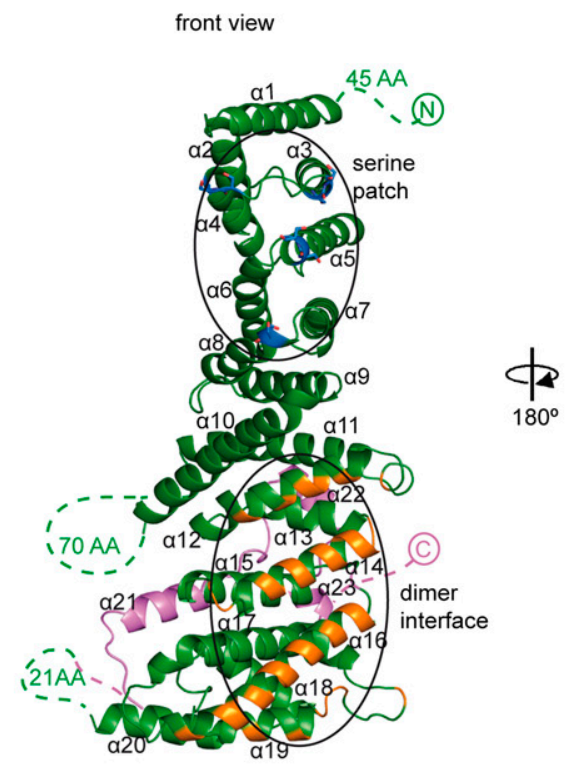

back view

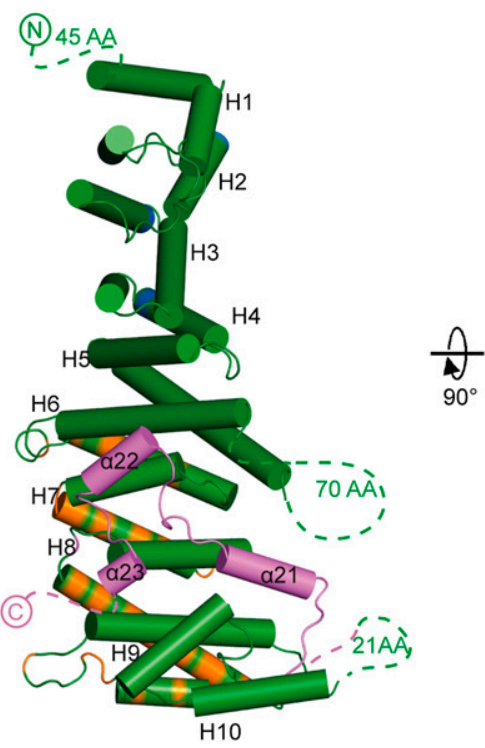

top view

Figure 1. Rrn3 has a HEAT repeat structure. (A) Alignment and conservation of Rrn3 amino acid sequences of S. cerevisiae (S.c.) and Homo sapiens (H.s.). Helical secondary structure elements are indicated above the sequences. Pairs of helices forming HEAT repeats $\mathrm{H} 1-\mathrm{H} 10$ are indicated as green bars. Disordered regions are labeled with black triangles below the alignment. Invariant and conserved residues are highlighted in green and yellow, respectively. Hydrophobic core residues are indicated with black bars, and dimer interface residues are indicated with orange bars above the alignment. Residues forming the "serine patch" are indicated with blue dots above the $S$. cerevisiae sequence. Phosphosites mapped in TIF-IA are labeled with red dots below the $H$. sapiens sequence. C-terminal helices are in pink. The cross-linked lysine K558 is indicated with a purple box. Sequence alignments were done with CLUSTALW2 (Larkin et al. 2007), and figures were prepared with ESPript (Gouet et al. 1999). (B) Ribbon and cylinder representations of the Rrn3 crystal structure. Secondary structure elements are labeled according to $A$. The C-terminal helices are highlighted in pink, and residues involved in dimerization are in orange. Residues forming the conserved serine patch are in blue. The three different views correspond to the standard polymerase views (front, back, and top) to facilitate comparison with the models shown in Figure 7 . This and other figures were prepared with PyMol (DeLano Scientific). 

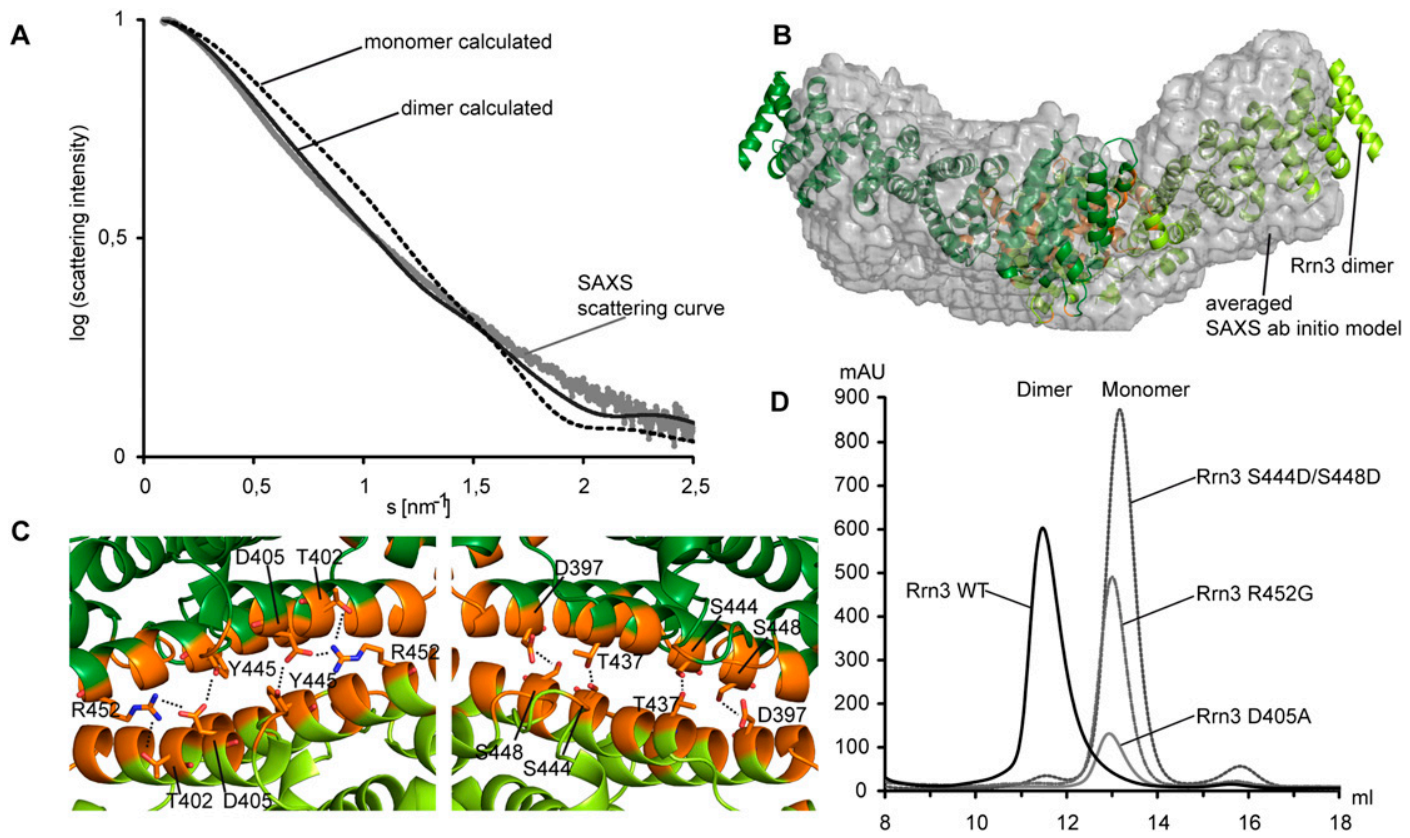

Figure 2. Rrn3 forms a homodimer in solution. (A) SAXS scattering curve for Rrn3 (light gray), and calculated (Svergun et al. 1995) scattering curves for monomeric (black dotted line) and dimeric (black line) Rrn3. (B) Ab initio SAXS envelope with docked Rrn3 homodimer structure. $(C)$ Crystallographic dimer interface. The two views are related by a $180^{\circ}$ rotation around a vertical axis. Interactions are indicated as dotted lines. Contact distances are within 2.8-3.5 $\AA$. (D) Size exclusion chromatography shows that Rrn3 mutations S444/S448D, D405A, and R452G disrupt the dimer interface and lead to monomerization. The elution profile of wild-type Rrn3 is in black, and profiles of mutants S444/448D, D405A, and R452G are in gray.

\section{Rrn3 binds Pol I as a monomer}

We next investigated whether Rrn3 binds to Pol I as a homodimer or whether the dimer is disrupted upon polymerase binding. Endogenous Pol I was purified with the use of a hexahistidine tag (Kuhn et al. 2007) and incubated with a ninefold molar excess of recombinant Rrn3 carrying a Strep-Tag (see the Materials and Methods). The Pol I-Rrn3 complex was separated from excess Rrn3 by Ni-NTA affinity chromatography and subjected to native mass spectrometry (MS) (Heck 2008). This revealed an MW of 667 $\mathrm{kDa}$ (Fig. 3), in agreement with a Pol I-Rrn3 monomer complex (663 kDa theoretical MW), but not with a Pol I-Rrn3 dimer complex (736 kDa). Dissociation of this complex in the mass spectrometer liberated subunit A49, showing that the A49/34.5 heterodimer, which is known to dissociate from Pol I (Huet et al. 1976; Geiger et al. 2010), is present in the 667-kDa complex. Native MS revealed a second complex with an MW of $593 \mathrm{kDa}$, which is explained by free Pol I (589 $\mathrm{kDa}$ theoretical MW) or by a Pol I-Rrn3 complex that lost the A49/34.5 heterodimer (589 kDa theoretical MW). The monomeric Rrn3 variants D405A and R452G still formed stable complexes with Pol I(data not shown). Together, these results show that Rrn3 binds Pol I as a monomer.

\section{A serine patch is required in vivo}

Parts of the Rrn3 surface are conserved and may be involved in protein interactions (Fig. 4). A total of eight serine residues, arranged in four pairs (S101/S102, S109/ S110, S145/S146, and S185/S186), cluster on the Rrn3 surface ("serine patch") (Fig. 4B). Six of these residues are conserved between yeast and humans (Fig. 1A). Residues S185 and S186 correspond to human residues S199 and T200, which are phosphorylated in vivo, preventing Pol I association and shutting down Pol I transcription (Mayer et al. 2004, 2005). To investigate whether the serine patch was required for yeast growth, we mutated all eight serines individually to alanine or aspartate, thereby disabling phosphorylation or mimicking a phosphorylated state, respectively. Complementation assays in a $\Delta r r n 3$ strain revealed that the Rrn3 mutation S145D causes severe slow growth on 5-FOA plates and in culture (Fig. 5A,B), whereas the other mutations had no effect (data not shown). The phenotype was enhanced in the presence of rapamycin, an inhibitor of the TOR kinase pathway that regulates Pol I, and in the presence of cycloheximide, an inhibitor of protein biosynthesis (Fig. 5A). This shows the importance of the serine patch, and in particular S145, for cell growth and suggests a conserved mechanism of Rrn3 phospho-regulation.

\section{The serine patch binds Pol I in vitro}

Since the interaction of Pol I with TIF-IA depends on the phosphorylation status of TIF-IA (Fath et al. 2001; Schlosser et al. 2002; Zhao et al. 2003; Mayer et al. 2004, 2005; Philimonenko et al. 2004; Bierhoff et al. 2008; Hoppe et al. 2009), we investigated whether the serine patch of Rrn3 is required for Pol I binding and whether phosphorylations in this patch influence binding. We expressed Rrn3 mutant S145D, which showed a growth defect in yeast (Fig. 5A), 


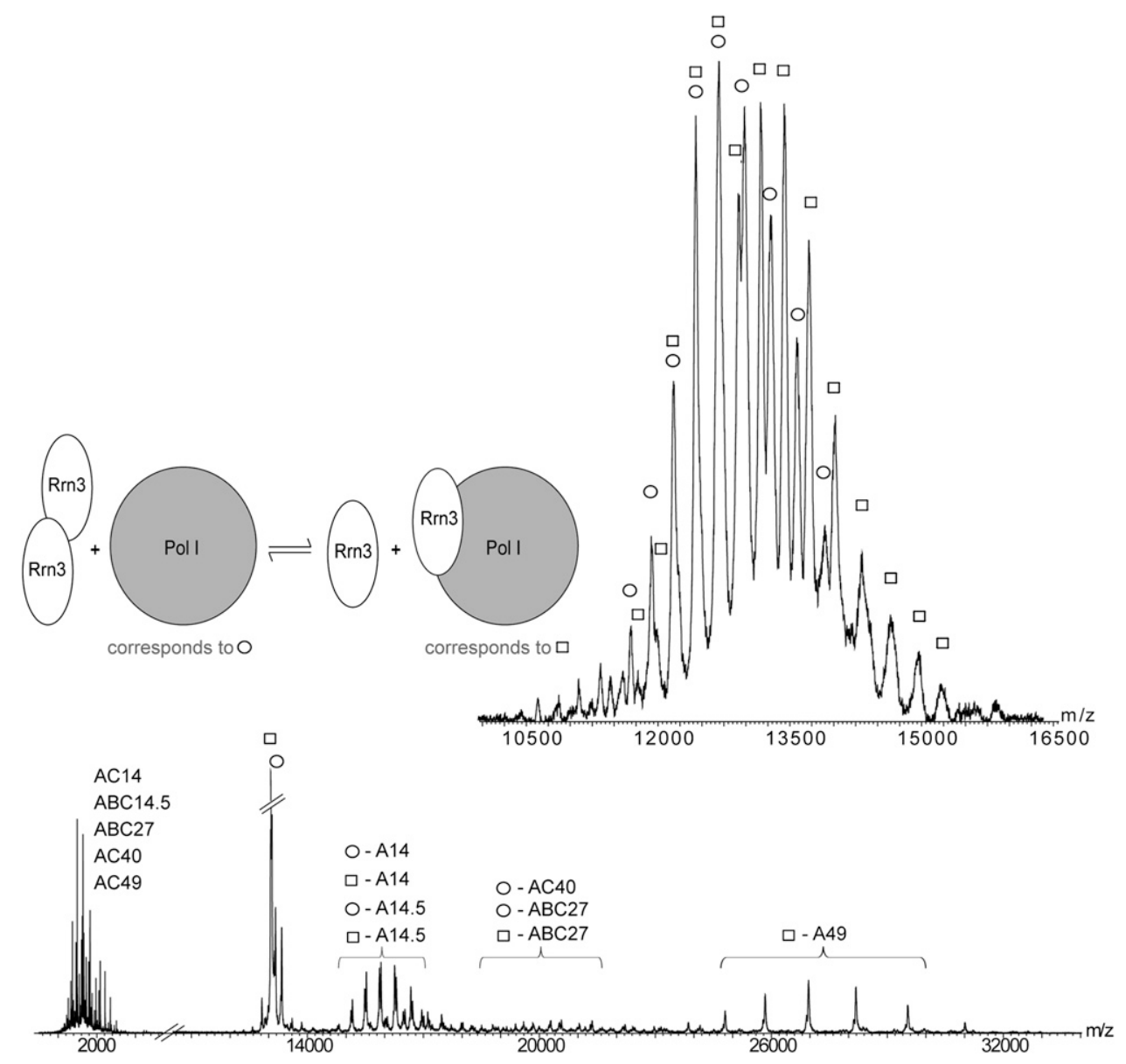

Figure 3. Rrn3 binds Pol I as a monomer. Native MS reveals that Rrn3 binds Pol I as a monomer. (Top panel) Two different charge distributions were detected with masses of 593 and $667 \mathrm{kDa}$, which refer to Pol I alone (or a Pol I $\Delta \mathrm{A} 49 / 34.5-\mathrm{Rrn} 3 \mathrm{complex}$ ) and a Pol I-Rrn3 monomer complex, respectively. Native MS spectra for free Pol I have been published earlier (Geiger et al. 2010). (Bottom panel) Tandem MS leads to elimination of subunit A49 from the 667-kDa complex and elimination of subunits A14, A14.5, and ABC27 from the $593-\mathrm{kDa}$ and $667-\mathrm{kDa}$ complexes. The $593-\mathrm{kDa}$ complex additionally eliminates AC40. The remaining Pol I subcomplexes are observed at corresponding high mass/charge values.

and mutant S185D, which corresponds to human S199D, which does not bind Pol I (Mayer et al. 2004). The purified Rrn3 mutants were tested for their ability to form stable complexes with Pol I after size exclusion chromatography (Fig. 5C). Whereas wild-type Rrn3 bound Pol I in these assays, Rrn3 mutant S145D did not, and mutant S185D bound only weakly (Fig. 5C). Thus, the serine patch of Rrn3 is involved in Pol I binding in vitro, and phospho-mimetic mutations in this patch can impair Pol I binding.

The serine patch functions in Pol I promoter recruitment

To investigate Pol I recruitment to the rDNA gene in vivo, we performed chromatin immunoprecipitation (ChIP) experiments. We prepared yeast strains with a tandem affinity purification (TAP) tag on Pol I subunit A190 and expressing Rrn3 wild-type or mutant S145D and determined Pol I occupancy at rDNA genes by ChIP (Fig. 6). Pol I occupancy at all tested regions of the rDNA locus was strongly decreased in the strain expressing Rrn3 mutant S145D (Fig. 6B), although protein levels were unchanged (Fig. 6D). This shows that normal Pol I recruitment to rDNA in vivo requires an unphosphorylated S145 residue on Rrn3. We also tested whether the S145D mutation impairs Rrn3 recruitment to rDNA. We complemented the $\Delta r r n 3$ strain with plasmids expressing TAP-tagged Rrn3 wild type or mutant S145D. ChIP revealed that wild-type Rrn3 localizes to the rDNA promoter and the beginning of the transcribed region as shown before (Bier et al. 2004; Claypool et al. 2004; Beckouet et al. 2008; Philippi et al. 2010), whereas occupancy with mutant S145D was decreased fivefold to 10 -fold (Fig. 6C). These results indicate that S145 phosphorylation impairs cooperative recruitment of Rrn3 and Pol I to the rDNA gene in vivo.

\section{Rrn3 binds Pol I near subcomplex AC40/19}

To elucidate the molecular basis for Pol I-Rrn3 binding, we subjected the Pol I-Rrn3 complex to chemical crosslinking and identified cross-linked lysines by MS (Leitner 

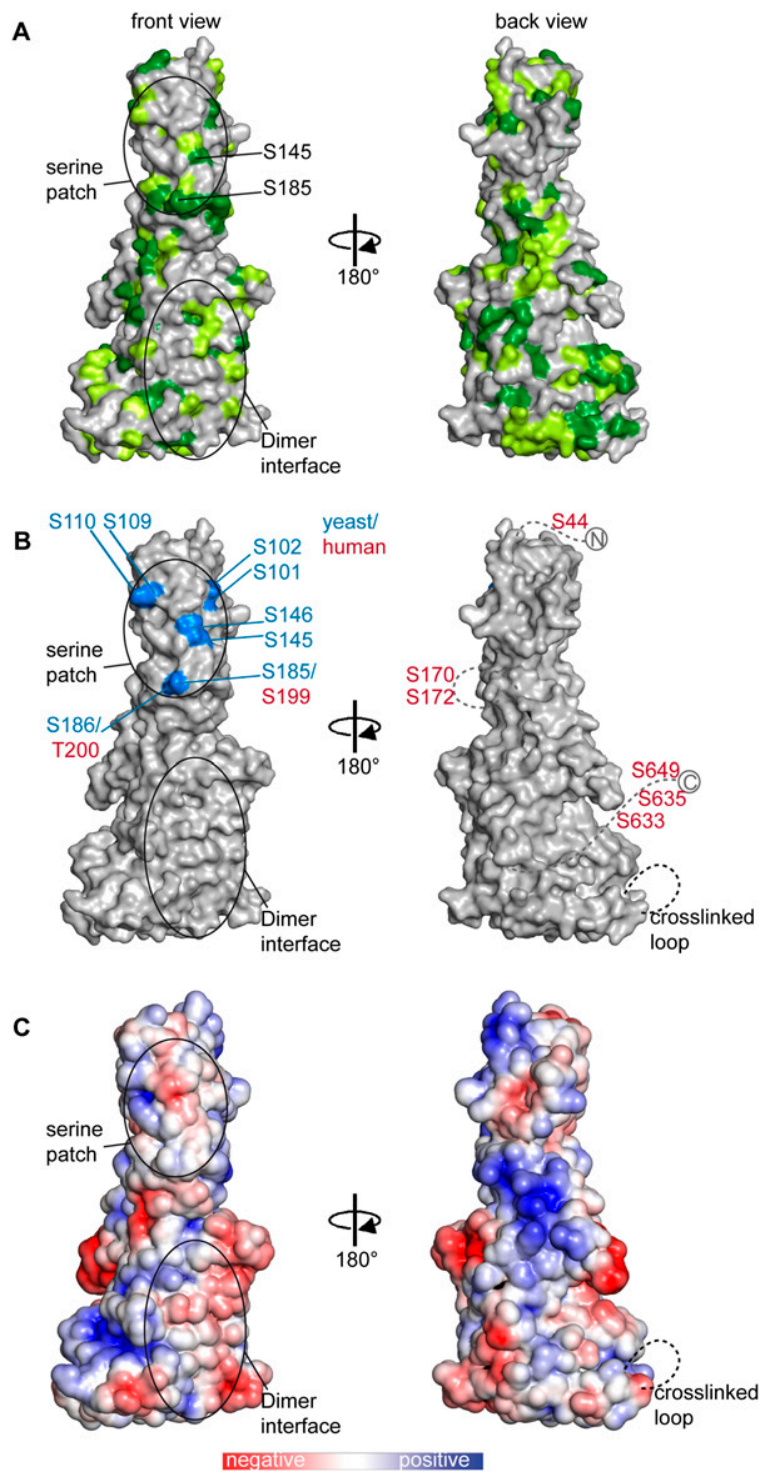

Figure 4. Rrn3 surface analysis reveals a serine patch. (A) Surface conservation. Identical and conserved residues are highlighted in dark and light green, respectively. Positions of residues S145 and S185 and the dimer interface are indicated. (B) Surface positions of residues in the serine patch (blue) and TIFIA phosphosites (red labels) mapped on the Rrn3 surface. $(C)$ Surface charge distribution. Red, blue, and white areas indicate negative, positive, and neutral charge, respectively.

et al. 2010). This can reveal proximal lysine residues on adjacent proteins and allows positioning of crystal structures to obtain topological models of large polymerasefactor complexes (Chen et al. 2010). A pure Pol I-Rrn3 complex was cross-linked with $1.2 \mathrm{mM}$ disuccinimidyl suberate, and cross-linked lysines were identified by MS (see the Materials and Methods). The MS data were of high quality, as cross-links between Pol I subunits were explained with the Pol I model (Kuhn et al. 2007) and the Pol II structure (Armache et al. 2005). Details of the crosslinks within Pol I and the cross-linking method will be described elsewhere. The analysis revealed two highconfidence cross-links between Rrn 3 and Pol I, connecting Rrn3 residue K558 to Pol I residues K582 and K329 in subunits A190 and AC40, respectively (Fig. 7A). The cross-linked Pol I residues are located on the "back" of the homologous Pol II structure near the Rpb3/11 heterodimer, which corresponds to the AC40/19 heterodimer.

\section{Model of the Pol I-Rrn3 complex}

To obtain a model for the Pol I-Rrn3 complex, we positioned the Rrn3 structure on the polymerase such that cross-links were explained (see the Materials and Methods). The cross-linked Rrn3 residue K558 is part of the short mobile loop $\alpha 20-\alpha 21$ that follows the ordered residue G554, which was allowed to be up to $30.9 \AA$ from crosslinked Pol I lysines (the theoretical maximum $\mathrm{C} \alpha$ distance of $27.4 \AA$ plus $3.5 \AA$ for mobile residues 555-558). Only one Rrn 3 orientation positioned the serine patch toward Pol I, to explain the interaction data without producing protein clashes (Fig. 7A). In the resulting model of the Pol I-Rrn3 complex, Rrn3 extends from the RNA exit tunnel and dock domain alongside A14/43, the counterpart of the Pol II subcomplex Rpb4/7, to AC40/19. The model explains Rrn3 binding to the OB domain of subunit A43 (Peyroche et al. 2000), an early electron microscopic projection (Peyroche et al. 2000), the observation that Rrn3 can be fused to A43 in vivo (Laferte et al. 2006), and an apparently stabilizing effect of A14 on the Rrn3-Pol I interaction (Imazawa et al. 2005).

\section{Rrn7 is a TFIIB-related factor}

The location of Rrn3 near the dock domain prompted us to search for a homolog of the Pol II factor TFIIB in the Pol I initiation machinery, since TFIIB binds the dock domain (Chen and Hahn 2003). We examined the three subunits of the Pol I core factor-Rrn6, Rrn7, and Rrn11-with the HHpred structure prediction server (Soding et al. 2005). This revealed a clear homology of the $\mathrm{N}$-terminal region of Rrn7 (residues 1-316) with TFIIB (E-value, 0.028; probability score, 93.6). The structured domains of TFIIB, the $\mathrm{N}$-terminal zinc ribbon, and the two C-terminal cyclin folds (Kosa et al. 1997; Tsai and Sigler 2000; Kostrewa et al. 2009) are predicted to be present in Rrn7 (Fig. 7B) and can be modeled (Eswar et al. 2008). The predicted Rrn7 ribbon domain contains all four zinc-binding cysteine residues, although the $\mathrm{C}$-terminal cysteine is replaced by a functionally equivalent histidine in some species. The C-terminal region of Rrn7 does not show homologies with known factors, similar to the TFIIB-related factor Brf1 in the Pol III system, which also contains a specific C-terminal region (Fig. 7B).

\section{Architecture of the Pol I initiation complex}

The prediction of a TFIIB-related factor in the Pol I initiation apparatus prompted us to extend the modeling to a minimal Pol I initiation complex (Fig. 7C,D). We assumed that Rrn7, TBP, and promoter DNA are positioned like TFIIB, TBP, and promoter DNA in the Pol II initiation complex model (Kostrewa et al. 2009), in agreement with 


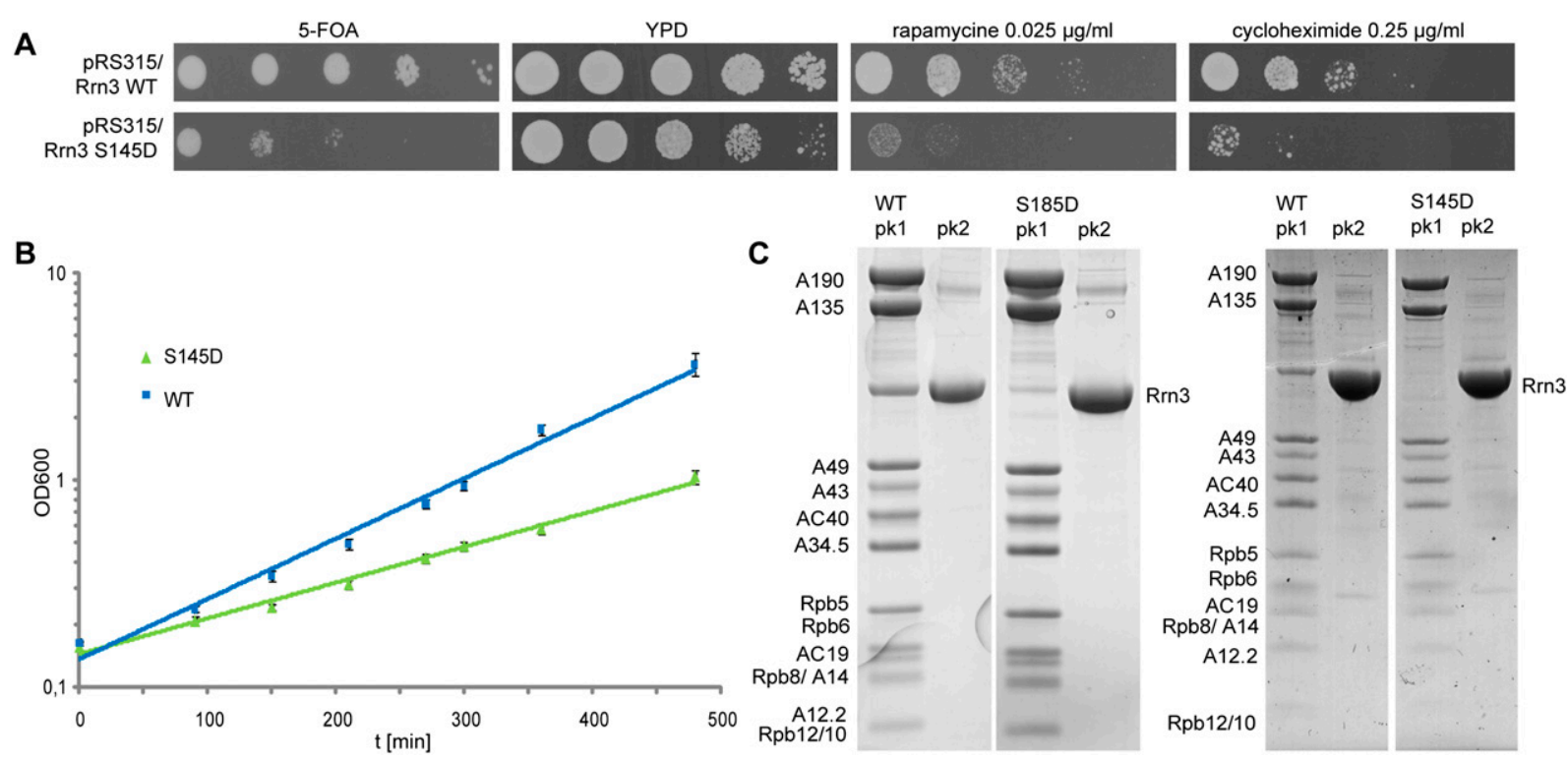

Figure 5. Rrn3 serine patch is required for cell growth and Pol I binding. (A) Yeast complementation assays reveal a critical function of Rrn3 residue S145 for cell growth. Rrn3 variants were cloned into a pRS315 vector by homologous recombination, transformed into the rrn3 shuffle strain, and streaked onto 5-FOA-containing plates to shuffle out the Rrn3-expressing URA3 plasmid. Growth of rrn3 mutants was further tested on plates containing $0.025 \mu \mathrm{g} / \mathrm{mL}$ rapamycin or $0.25 \mu \mathrm{g} / \mathrm{mL}$ cycloheximide. (B) A yeast strain expressing the Rrn3 mutant S145D exhibits a slow-growth phenotype in liquid culture (green). Growth of the same strain under the same conditions but expressing wild-type Rrn3 from the same plasmid is shown in blue (WT). (C) The serine patch is required for Pol I binding in vitro. Pol I was incubated with excess wild-type or mutant Rrn3 and subjected to size exclusion chromatography, which revealed two separated peaks (pk1 and pk2) that were analyzed with Coomassie-stained SDS-PAGE. In contrast to wild-type Rrn3 (WT), which forms a stable complex with Pol I in these assays, the Rrn3 mutants S185D and S145D bind Pol I weakly or not at all (pk1). The second peak corresponded to free excess Rrn3 proteins (pk2).

a known Rrn7-TBP interaction (Lalo et al. 1996). The resulting model revealed that the $\mathrm{N}$-terminal zinc ribbon domain of Rrn7 that is bound to the polymerase dock domain could contact Rrn3 (Fig. 7C,D), perhaps explaining the known interaction between the human homologs of Rrn3 and Rrn7 (Miller et al. 2001). The model further indicates that the two other subunits of the core factor, Rrn6 and Rrn11, occupy positions between the Pol I clamp and subcomplexes A14/43 and the dock domain, as this explains known interactions of Rrn3 with Rrn6 in yeast (Peyroche et al. 2000) and in the human system (Miller et al. 2001).

\section{Discussion}

Here we used a combination of structural and functional techniques to elucidate the mechanism of Rrn3-regulated Pol I initiation and cell growth. The structure of Rrn3 reveals a unique HEAT repeat fold and a conserved surface serine patch. Rrn3 forms a dimer in solution, but binds Pol I as a monomer that extends along the back of Pol I between subcomplexes AC40/19 and A14/43. The Rrn3 serine patch faces the Pol I subunit A43 and its phosphorylation impairs cell growth, Pol I binding in vitro, and Pol I recruitment to the rDNA gene in vivo. Bioinformatics identifies Rrn7 as a putative functional homolog of TFIIB, leading to a model of a minimal Pol I-Rrn3 initiation complex.
These results converge with published data on the molecular basis for Pol I initiation regulation by Rrn3. During normal cell growth, the Rrn3 serine patch is not phosphorylated, enabling Rrn3 to bind Pol I and resulting in stable Pol I recruitment to rDNA and transcription. During stress, phosphorylation of the serine patch impairs Rrn3 interaction with Pol I and Pol I recruitment to rDNA, down-regulating Pol I transcription, ribosome production, and cell growth. The phosphorylation of serine patch residues in human TIF-IA (Mayer et al. 2004, 2005) argues for a conserved phospho-regulation of the Pol I-Rrn3 interaction and Pol I initiation, although we could not map the phosphorylation sites on endogenous yeast Rrn3 despite extensive efforts using either exponentially growing cells or cells entering stationary phase (data not shown).

Phosphorylation of TIF-IA also occurs outside the conserved serine patch (Fig. 4B; Zhao et al. 2003; Philimonenko et al. 2004; Bierhoff et al. 2008; Hoppe et al. 2009). Phosphorylation of residues S633 and S649 in the TIF-IA C-terminal tail activates transcription (Zhao et al. 2003), and S635 phosphorylation abolishes TIF-IA interaction with the human core factor (Hoppe et al. 2009), consistent with our model, which indicates that the TIF-IA C-terminal region that is not present in yeast $\mathrm{Rrn} 3$ could be near the predicted core factor location (Fig. 7C,D). Phosphorylation of the N-terminal serine S44 activates mammalian TIF-IA (Mayer et al. 2004), whereas in Rrn3, 
A

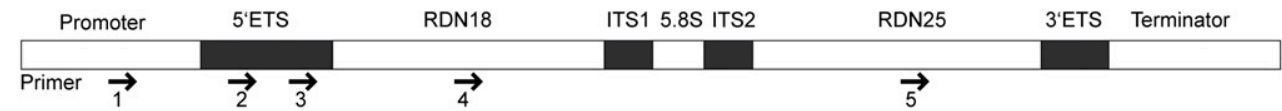

B
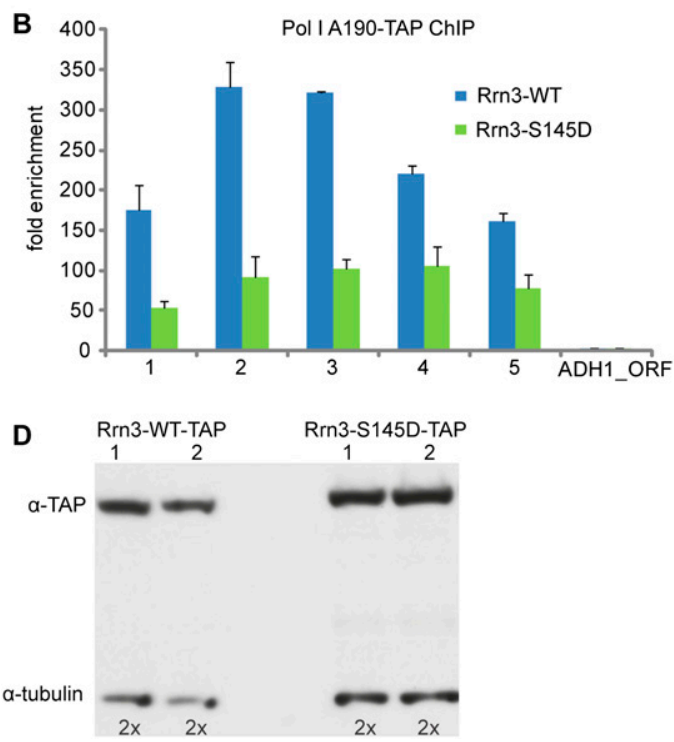

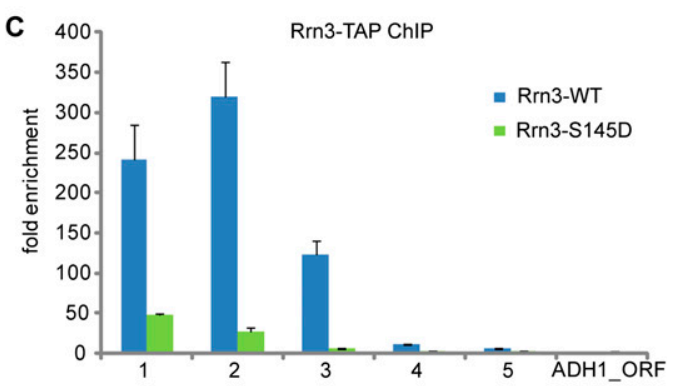

Figure 6. The Rrn3 serine patch recruits Pol I to genes. (A) For ChIP analysis, primer pairs complementary to five regions of the rDNA locus were used (indicated by arrows). (ETS) External transcribed spacer; (ITS) internal transcribed spacer; (RDN18) region encoding the 18 S rRNA; (RDN25) region encoding the 25S rRNA. (B) ChIP analysis shows that the Rrn3 S145D mutation reduces Pol I occupancy at the rDNA locus. ChIP was carried out with haploid strain Y24975 ( $\Delta r r n 3$ ) expressing a plasmid encoding either Rrn3 wild type (WT) or Rrn3 mutant S145D and carrying a C-terminal TAP tag on Pol I subunit A190. ChIP intensities over background are shown in a bar diagram. Errors were estimated from two biological replicate measurements. As a negative control, we used primers complementary to the ORF of the Pol II transcribed gene adh1 (ADH1_ORF). (C) The Rrn3 S145D mutation reduces Rrn3 occupancy at the rDNA locus. ChIP was performed with a strain expressing the C-terminally TAP-tagged Rrn3 mutant S145D from plasmid pRS315. (D) Rrn3 S145D mutation does not change cellular Rrn3 protein levels according to Western blot analysis with TAP-tagged Rrn3 variants. The ratio of Western blot signals for Rrn3 and tubulin was twofold throughout, as calculated with ImageQuant TL 7.0 image analysis software (GE Healthcare).

a complete deletion of its $47 \mathrm{~N}$-terminal residues had no effect in complementation assays (data not shown). Phosphorylations at S170 and S172 are required for TIFIA dissociation from elongating Pol I (Bierhoff et al. 2008) and may interfere with exiting RNA, which is predicted to displace the Rrn7 zinc ribbon (Fig. 7C). Rrn3 dissociation also requires the A49/34.5 subcomplex (Beckouet et al. 2008; Albert et al. 2011), but it is unclear why. The Pol I-Rrn3 interaction is additionally regulated through phosphorylation of the Pol I subunit A43 (Fath et al. 2001) that faces Rrn3. Taken together, current data converge on the view that both Rrn3 and TIF-IA are regulated by phosphorylation on a conserved surface serine patch, but that distinct phosphorylations in TIF-IA-specific regions and on Pol I may contribute to function.

Rrn3 apparently also has a post-recruitment function, since Pol I can be recruited without Rrn3 at low levels, but requires Rrn3 for initiation (Schnapp and Grummt 1991; Schnapp et al. 1993; Aprikian et al. 2001). We predict that Rrn3 binding causes a conformational change in Pol I that induces an initiation-competent state. Electron microscopy of free Pol I revealed a "collapsed state" of the clamp (Kuhn et al. 2007) that would prevent the DNA template strand from entering the active center cleft. Rrn3 binding, however, may hold the clamp in a position that allows template loading. Clamp positioning may involve Pol I-specific surface features of the clamp and dock domains (Kuhn et al. 2007).

Our results also suggest that cells contain a reservoir of Rrn3 dimers that do not bind Pol I. The presence of serine residues S444 and S448 in the dimer interface further suggested that interface phosphorylation could release Rrn3 monomers that bind Pol I. However, the phospho-mimetic dimer-disrupting Rrn3 mutation S444/S448D (Fig. 2D) has no phenotype in yeast (data not shown), providing, at present, no evidence for regulated Rrn3 dimerization in vivo.

Finally, we provide the long-sought unifying evolutionary view of transcription initiation in eukaryotic cells. It was always puzzling why the Pol I system lacks a factor related to TFIIB, since it requires TBP and since transcription initiation by archaeal Pol, Pol II, and Pol III requires TBP and TFIIB homologs. The previously undetected predicted homology of the core factor subunit Rrn7 with TFIIB provides this missing link. Since regions in Pol I and Pol III subunits resemble parts of the Pol II initiation factors TFIIE and TFIIF (Geiger et al. 2010; Kassavetis et al. 2010; Vannini et al. 2010; Lefevre 
A

A

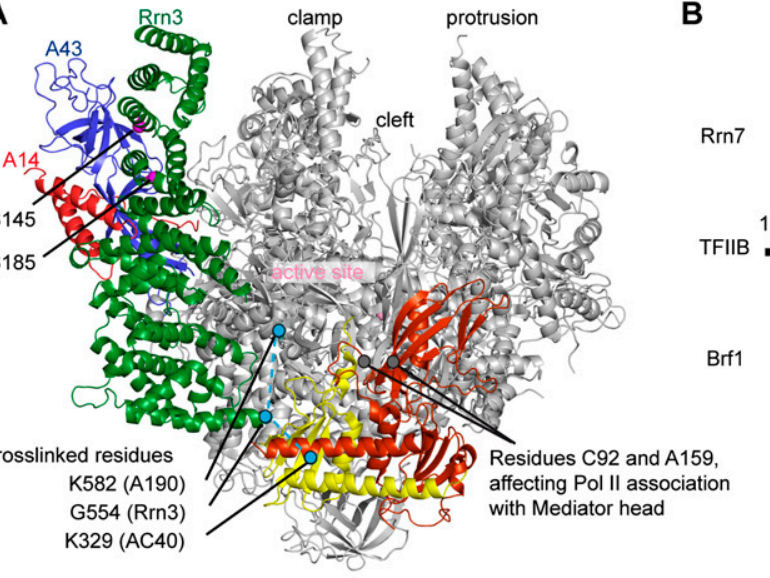

B

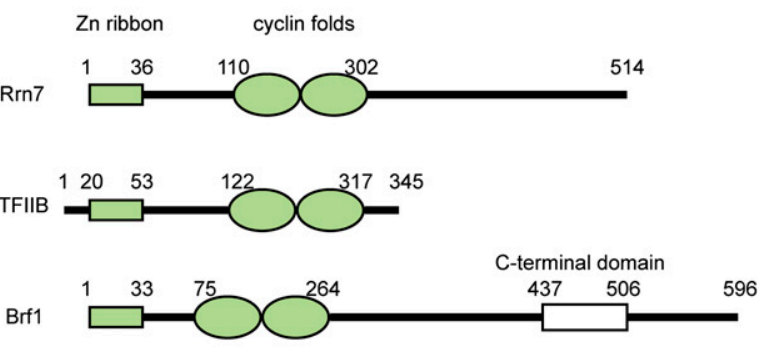

C

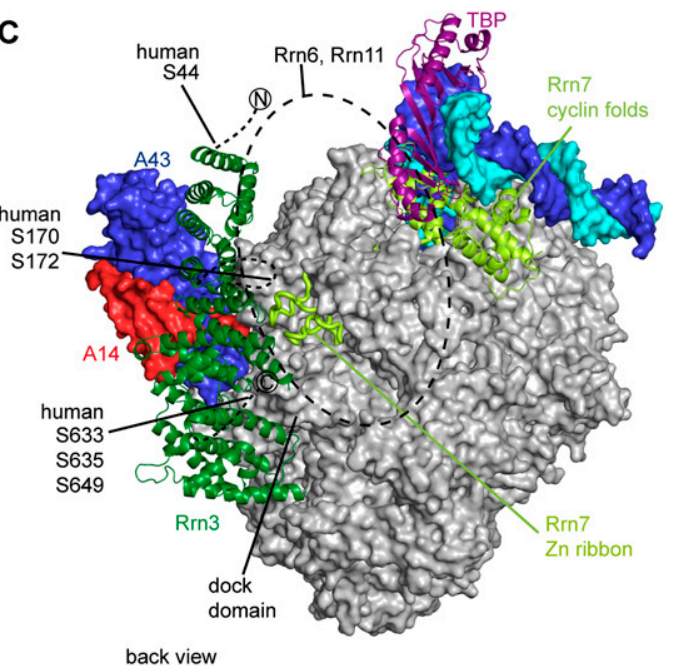

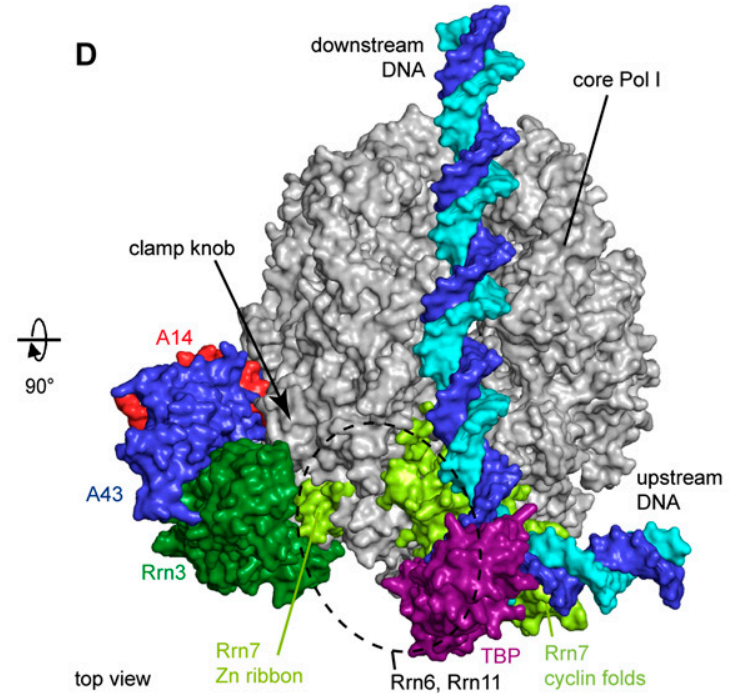

Figure 7. Model of the Pol I-Rrn3 initiation complex. (A) Model of the Pol I-Rrn3 complex based on lysine-lysine cross-linking and protein interaction data. Back view of a 12-subunit Pol I model that is based on the Pol II core structure (silver) (Armache et al. 2005) and the structure of subcomplex A14/43 (red/blue) (Kuhn et al. 2007). The Pol II core heterodimer Rpb3/11 that is homologous to the Pol I heterodimer AC40/19 is highlighted in red/yellow. The positioned Rrn3 structure (green) contains a lysine residue (K558) that is part of a short mobile loop following the ordered residue G554 (cyan dot) and cross-links to two Pol I residues (cyan dots connected with dashed lines). Cross-linked positions in the Pol I core are revealed in the homologous Pol II structure; K582 in A190 corresponds to M437 in Rpb1, and K329 in AC40 corresponds to L259 in Rpb3 (cyan dots). Positions C92 and A159 in Rpb3, influencing the interaction of Pol II with the Mediator head module (Soutourina et al. 2011), are indicated as gray spheres. (B) Rrn7 is the TFIIB homolog in the Pol I system. Schematic representation of distinct structural domains in TFIIB and the homologous factors Rrn7 and Brf1 in the Pol I and Pol III systems, respectively. All three proteins exhibit an N-terminal zinc ribbon followed by two conserved cyclin folds. In addition, Rrn7 and Brf1 contain a specific C-terminal region. $(C)$ Model of a minimal Pol I initiation complex. The Pol I-Rrn3 model in $A$ was combined with the Pol II minimal initiation complex model containing TFIIB (light green, serving as a model for Rrn7), TBP (magenta), and closed promoter DNA (blue/cyan) (Kostrewa et al. 2009). Pol I and DNA are represented as molecular surfaces, whereas TBP, the Rrn7 model, and Rrn3 are shown as ribbons. The presumed location of the remaining core factor subunits Rrn6 and Rrn11 are indicated with a dashed circle. The view is from the back. Positions of phosphorylated serines S170, S172, and S635 in human TIF-IA are indicated. $(D)$ Top view of the model in $C$ containing all proteins in surface representation.

et al. 2011), it now appears that the initiation complexes of both Pol I and Pol III resemble the core of the Pol II-TBP$\mathrm{TFIIB} / \mathrm{E} / \mathrm{F}$ complex. The similarity in transcription initiation complex topology may extend to regulatory cofactors. Electron microscopy and cross-linking indicate that the Mediator head binds at the Rpb3/11 subcomplex of Pol II (Takagi et al. 2006; Soutourina et al. 2011), a position resembling the location of Rrn3 on Pol I, and mechanistic studies show that
Mediator interacts directly with TFIIB (Baek et al. 2006). Thus, regulatory cofactors differ in structure, but may use the same molecular targets on conserved core initiation complexes. It came to our attention during the revision of this manuscript that studies demonstrating a functional homology between Rrn7 or its human ortholog with TFIIB and Brf1 were accepted for publication (Knutson and Hahn 2011; Naidu et al. 2011). 


\section{Materials and methods}

\section{Protein sample preparation}

S. cerevisiae Rrn3 was cloned into a pET28b plasmid, resulting in an N-terminal hexahistidine tag-or in pET21b-with an $\mathrm{N}$-terminal Strep-Tag. Proteins were expressed in Escherichia coli BL21 (DE3) RIL cells (Stratagene) in autoinducing medium (TB) for $16 \mathrm{~h}$ at $24^{\circ} \mathrm{C}$. Cells were harvested, washed with PBS, and lysed by sonication. The lysate was centrifuged, and the supernatant was loaded on a Ni-NTA (Qiagen) column equilibrated in buffer A $(50 \mathrm{mM}$ HEPES at pH 7.8, $200 \mathrm{mM} \mathrm{NaCl}, 3 \mathrm{mM}$ DTT, $10 \%$ glycerol). The column was washed with buffer A containing 20-50 mM imidazol, and protein was eluted with buffer A containing $150 \mathrm{mM}$ imidazol. Proteins carrying a Strep-Tag were bound to a $1-\mathrm{mL}$ Strep-tactin Sepharose column (IBA) equilibrated in buffer A and eluted with buffer A containing $2.5 \mathrm{mM}$ d-desthiobiotin. Proteins were purified by anion exchange chromatography (Mono Q, GE Healthcare). The column was equilibrated in buffer B $(50 \mathrm{mM}$ HEPES at $\mathrm{pH} 7.8,5 \mathrm{mM} \mathrm{DTT}, 10 \%$ glycerol), and proteins were eluted with a linear gradient of 20 column volumes from $100 \mathrm{mM}$ to $1 \mathrm{M} \mathrm{NaCl}$. After concentration, the sample was applied to a Superdex 200 size exclusion column (GE Healthcare) equilibrated with buffer C $(50 \mathrm{mM}$ HEPES at $\mathrm{pH} 7.8,300 \mathrm{mM} \mathrm{NaCl}, 5 \mathrm{mM}$ DTT). Pooled peak fractions were concentrated to $10 \mathrm{mg} / \mathrm{mL}$. Purification of Pol I was as described (Kuhn et al. 2007), except that buffers contained phosphatase inhibitors $(2 \mathrm{mM}$ Na-pyrophosphate, $5 \mathrm{mM} \beta$-phosphoglycerate, $50 \mathrm{mM} \mathrm{NaF}$ ). For assembly of the Pol I-Rrn3 complex, Pol I was incubated with a ninefold molar excess of Rrn3 overnight on ice, followed by size exclusion chromatography and concentration of the fractions containing the complex.

\section{Crystal structure determination}

Crystals of Rrn 3 were grown at $20^{\circ} \mathrm{C}$ in hanging drops over a reservoir solution containing 14\% PEG 3350 and $250 \mathrm{mM}$ sodium-potassium-tartrate. Crystals were cryo-protected by a stepwise transfer to a reservoir solution containing 5\%-20\% PEG 200 and flash-cooled in liquid nitrogen. Crystals were soaked in a reservoir solution containing $10 \mathrm{mM}$ thiomersal for 8-15 min, transferred to the solutions containing additionally the cryoprotectant, and flash-frozen in liquid nitrogen. Diffraction data were obtained on a PILATUS 6M detector at the Swiss Light Source in Villigen, Switzerland, and processed with XDS (Table 1; Kabsch 1993). SHELXD (Schneider and Sheldrick 2002; Pape and Schneider 2004) detected two mercury sites. SHARP (de La Fortelle and Bricogne 1997) was used for MAD phasing. Initial model building was performed with Buccaneer (Cowtan 2006), and rebuilding was performed with COOT (Emsley and Cowtan 2004). Refinement was carried out with PHENIX (Afonine et al. 2005) and BUSTER (Blanc et al. 2004).

\section{SAXS}

Proteins were purified as above, but concentrated to 2 or $8 \mathrm{mg} /$ $\mathrm{mL}$ in buffer $\mathrm{C}$. The flow-through of the concentration step was used as buffer reference for SAXS. SAXS data were collected at beamline X33 at EMBL/DESY, Hamburg, Germany. BSA and lysozyme were measured as references for molecular mass determination from Io obtained from extrapolation of $s \rightarrow 0$ in Guinier analysis with $s \times \mathrm{Rg}<1.3$ (Putnam et al. 2007). The ATSAS package (Konarev et al. 2006) was used to analyze data. Theoretical scattering profiles from known structures were calculated and fitted to measured profiles with CRYSOL. Ab initio modeling from the experimental data was performed with DAMMIF and GASBOR without imposing symmetry or other restrictions. Models were aligned, filtered, and averaged with SUPCOMB and DAMAVER (Volkov and Svergun 2003). Envelope representations were calculated with SITUS (Wriggers and Chacon 2001).

\section{Native MS}

For native MS, the sample buffer was exchanged to a solution containing $200 \mathrm{mM}$ ammonium acetate using centrifugal filter units (Millipore), and sample concentration was adjusted to $2 \mu \mathrm{M}$. MS was carried out on a Q-ToF I instrument (van den Heuvel et al. 2006; Geiger et al. 2010). The cone voltage was $150 \mathrm{~V}$ and the needle voltage was $1.3 \mathrm{kV}$. The pressure in the source region was $10 \mathrm{mbar}$. Xenon was used as a collision gas with a pressure of $2 \times$ $10^{-2}$ mbar (Lorenzen et al. 2007). Data were analyzed with MassLynx (Waters).

\section{Yeast genetic manipulations}

Strain Y24975 (BY4743; Mat a/a; his3D1/his3D1; leu2D0/leu2D0; lys2D0/LYS2; MET15/met15D0; ura3D0/ura3D0; YKL125w:: kanMX4/YKL125w) (Euroscarf) was used for genetic modifications. Rrn3 with a native promoter region was cloned into pRS316 plasmid carrying the $U R A 3$ gene, allowing growth on minimal selective medium. The diploid strain, carrying the rrn3 deletion on a haploid genome, was transformed with pRS316-Rrn3. The diploid strain was sporulated, and tetrads were dissected on YPD plates. Clones were selected that carried a kanMX4 cassette replacing Rrn3 in the haploid genome. The resulting strains contain the pRS316 plasmid with a copy of Rrn3-WT under a native promoter. Rrn3 mutants were cloned into pRS315 containing the LEU2 gene. The strain was transformed with the pRS315 plasmid and selected on -LEU plates.

\section{Protein cross-linking and MS}

Pol I was purified as described (Kuhn et al. 2007), except that size exclusion chromatography (Superose 6 10/300, GE Healthcare) was performed in a buffer containing $20 \mathrm{mM}$ HEPES (pH 7.8), 300 $\mathrm{mM}$ potassium acetate $(\mathrm{KOAc}), 1 \mathrm{mM} \mathrm{MgCl}{ }_{2}, 10 \%$ glycerol, and $5 \mathrm{mM}$ DTT. Pol I fractions were pooled and concentrated to $1 \mathrm{mg} /$ $\mathrm{mL}$. The Pol I-Rrn3 complex was prepared as above and crosslinked using isotopically coded disuccinimidyl suberate (DSS-H12/ D12, Creative Molecules, Inc.). The purified Pol I-Rrn3 complex $(100 \mu \mathrm{L}$ containing $110 \mu \mathrm{g})$ was mixed with $25 \mathrm{mM}$ DSS dissolved in dimethylformamide (DMF) (Pierce Protein Research Products) to a final DSS concentration of $1.2 \mathrm{mM}$, and incubated at $350 \mathrm{rpm}$ for $30 \mathrm{~min}$ at $30^{\circ} \mathrm{C}$. The reaction was stopped by addition of $\mathrm{NH}_{4} \mathrm{HCO}_{3}$ to $100 \mathrm{mM}$ and incubation for $15 \mathrm{~min}$ at $30^{\circ} \mathrm{C}$. Cross-linked proteins were treated with two sample volumes of 8 $\mathrm{M}$ urea and reduced and alkylated using $5 \mathrm{mM}$ Tris(2-carboxyethyl)phosphine (TCEP) and $10 \mathrm{mM}$ iodoacetamide, respectively. The sample was digested with trypsin. MS analysis was as described (Leitner et al. 2010). The fragment ion spectra were assigned to cross-linked peptides using xQuest (Rinner et al. 2008). More details will be described elsewhere.

\section{ChIP}

S. cerevisiae strain Y24975 was grown in $50 \mathrm{~mL}$ of YPD medium at $30^{\circ} \mathrm{C}$ to mid-log phase $\left(\mathrm{OD}_{600} \sim 0.8\right)$ and treated with formaldehyde ( $1 \%$, Sigma F1635) for $20 \mathrm{~min}$ at $20^{\circ} \mathrm{C}$, and cross-linking was quenched with $5 \mathrm{~mL}$ of $3 \mathrm{M}$ glycine for $10 \mathrm{~min}$. Subsequent steps were performed at $4^{\circ} \mathrm{C}$ with precooled buffers containing protease inhibitors ( $1 \mathrm{mM}$ leupeptin, $2 \mathrm{mM}$ pepstatin A, $100 \mathrm{mM}$ phenylmethylsulfonyl fluoride, $280 \mathrm{mM}$ benzamidine). Cells 
were collected by centrifugation and washed twice with $1 \times$ TBS (20 mM Tris- $\mathrm{HCl}$ at $\mathrm{pH} 7.5,150 \mathrm{mM} \mathrm{NaCl}$ ) and twice with FA lysis buffer (50 mM HEPES-KOH at pH 7.5, $150 \mathrm{mM} \mathrm{NaCl}, 1 \mathrm{mM}$ EDTA, 1\% Triton X-100, 0.1\% sodium deoxycholate, $0.1 \%$ SDS). Pellets were flash-frozen in liquid nitrogen and stored at $-80^{\circ} \mathrm{C}$. Pellets were thawed, resuspended in $1 \mathrm{~mL}$ FA lysis buffer, and disrupted by bead beating (Retsch) in the presence of $1 \mathrm{~mL}$ of silica-zirconia beads for $30 \mathrm{~min}$ at $4^{\circ} \mathrm{C}$. Chromatin was solubilized and fragmented via sonication with a Bioruptor UCD-200 (Diagenode, Inc.). A 700- $\mu \mathrm{L}$ sample was immunoprecipitated with $20 \mu \mathrm{L}$ of IgG Sepharose 6 Fast Flow beads (GE Healthcare) for $1 \mathrm{~h}$ at $4^{\circ} \mathrm{C}$. Immunoprecipitated chromatin was washed three times with FA lysis buffer, twice with FA lysis buffer containing 500 $\mathrm{mM} \mathrm{NaCl}$, twice with ChIP wash buffer $(10 \mathrm{mM}$ Tris- $\mathrm{HCl}$ at $\mathrm{pH}$ 8.0, $0.25 \mathrm{M} \mathrm{LiCl}, 1 \mathrm{mM}$ EDTA, $0.5 \% \mathrm{NP}-40,0.5 \% \mathrm{Na}$ deoxycholate), and once with TE buffer (10 mM Tris-HCl at $\mathrm{pH} 7.4,1$ $\mathrm{mM}$ EDTA). Immunoprecipitated chromatin was eluted for 10 min at $65^{\circ} \mathrm{C}$ with ChIP elution buffer $(50 \mathrm{mM}$ Tris- $\mathrm{HCl}$ at $\mathrm{pH} 7.5$, $10 \mathrm{mM}$ EDTA, 1\% SDS) and digested with proteinase K (Sigma) for $2 \mathrm{~h}$ at $37^{\circ} \mathrm{C}$, and cross-links were reversed overnight at $65^{\circ} \mathrm{C}$. DNA was purified with the QIAquick PCR Purification kit (Qiagen). Input and immunoprecipitated samples were assayed by quantitative PCR (qPCR) using primer pairs directed against different regions of the first repeat within the RDN1 locus (Fig. 6). PCR reactions contained $1 \mu \mathrm{L}$ of DNA template, $2 \mu \mathrm{L}$ of $10 \mu \mathrm{M}$ primer pairs, and $12.5 \mu \mathrm{L}$ of iTaq SYBR Green Supermix (Bio-Rad). qPCR was performed on a Bio-Rad CFX96 Real-Time system (Bio-Rad Laboratories, Inc.) using a 3-min denaturing step at $95^{\circ} \mathrm{C}$, followed by 49 cycles of $30 \mathrm{sec}$ at $95^{\circ} \mathrm{C}, 30 \mathrm{sec}$ at $61^{\circ} \mathrm{C}$, and $15 \mathrm{sec}$ at $72^{\circ} \mathrm{C}$. Threshold cycle $(\mathrm{Ct})$ values were determined by application of the corresponding Bio-Rad CFX Manager software version 1.1 using the $C t$ determination mode "Regression." Fold enrichment of any given region over a nontranscribed heterochromatic region on chromosome V was determined as described (Fan et al. 2008).

\section{Protein expression analysis}

Expression levels of the TAP-tagged proteins were estimated by resolving the total protein from cell lysate by SDS-PAGE $(4 \%-12 \%$ $[\mathrm{w} / \mathrm{v}]$ polyacrylamide gel, Invitrogen) and blotting onto a PVDF membrane. The membrane was probed with antibodies against the TAP tag (PAP, Sigma) and tubulin (3H3087, Santa Cruz Biotechnology). Bound antibodies were detected by chemoluminescence (ECL Plus Western blotting detection system, GE Healthcare). For tubulin, peroxidase-conjugated AffiniPure rabbit anti-rat IgG $(\mathrm{H}+\mathrm{L})$ (Jackson ImmunoResearch) was used for detection. Detection was carried out with the LAS3000 detection system (Fuji), and signals were quantified in relation to the tubulin loading control using the ImageQuant TL 7.0 image analysis software (GE Healthcare). TAP-tagged strains were grown at $30^{\circ} \mathrm{C}$ in YPD medium to an $\mathrm{OD}_{600}$ of $\sim 0.8$. One milliliter of culture was pelleted by centrifugation $\left(4000 \mathrm{rpm}\right.$ for $2 \mathrm{~min}$ at $20^{\circ} \mathrm{C}$; Rotana 460R, Hettich). The supernatant was discarded, and the pellets were used for Western blot analysis.

\section{Accession numbers}

The coordinate file and structure factors for the Rrn3 crystal structure were deposited in the Protein Data Bank under accession code $3 \mathrm{TJ} 1$.

\section{Acknowledgments}

We thank D. Kostrewa, S. Benkert, A. Imhof (Zentrallabor für Proteinanalytik), T. Fröhlich (LAFUGA), K. Leike, and H. Feldmann for help. We acknowledge the crystallization facility at the MPI of Biochemistry, Martinsried. Part of this work was performed at the Swiss Light Source at the Paul Scherrer Institut, Villigen, Switzerland. We thank the staff of EMBL/DESY X33 for excellent support during SAXS data collection. This work was supported in part by funding from the European Union Seventh Framework Program PROSPECTS (Proteomics Specification in Space and Time Grant HEALTH-F4-2008-201648). C.B. acknowledges the International Max Planck Research School "From Biology to Medicine." We thank Steve Hahn and Joost Zoomerdijk for communicating results prior to publication. P.C. was supported by the Deutsche Forschungsgemeinschaft, SFB646, TR5, FOR1068, the Nanosystems Initiative Munich, an Advanced Investigator Grant of the European Research Council, the Elitenetzwerk Bayern, and the Jung-Stiftung. C.B. carried out experiments, except X-ray structure determination, which was carried out by C.B. and A.C.M.C.; SAXS analysis, which was carried out by G.W.; native MS, which was carried out by K.L.; protein cross-linking MS analysis, which was carried out by S.J. and F.H.; and ChIP analysis, which was carried out by A.M. K.P.H., A.J.R.H., and R.A. supervised SAXS, native MS, and cross-linking MS, respectively. P.C. designed the project and supervised other research. C.B. and P.C. wrote the manuscript.

\section{References}

Afonine PV, Grosse-Kunstleve RW, Adams PD. 2005. A robust bulk-solvent correction and anisotropic scaling procedure. Acta Crystallogr D Biol Crystallogr 61: 850-855.

Albert B, Leger-Silvestre I, Normand C, Ostermaier MK, PerezFernandez J, Panov KI, Zomerdijk JC, Schultz P, Gadal O. 2011. RNA polymerase I-specific subunits promote polymerase clustering to enhance the rRNA gene transcription cycle. J Cell Biol 192: 277-293.

Aprikian P, Moorefield B, Reeder RH. 2001. New model for the yeast RNA polymerase I transcription cycle. Mol Cell Biol 21: 4847-4855.

Armache KJ, Mitterweger S, Meinhart A, Cramer P. 2005. Structures of complete RNA polymerase II and its subcomplex, Rpb4/7. J Biol Chem 280: 7131-7134.

Baek HI, Kang YK, Roeder RG. 2006. Human Mediator enhances basal transcription by facilitating recruitment of transcription factor IIB during preinitiation complex assembly. I Biol Chem 281: 15172-15181.

Beckouet F, Labarre-Mariotte S, Albert B, Imazawa Y, Werner M, Gadal O, Nogi Y, Thuriaux P. 2008. Two RNA polymerase I subunits control the binding and release of Rrn3 during transcription. Mol Cell Biol 28: 1596-1605.

Bier M, Fath S, Tschochner H. 2004. The composition of the RNA polymerase I transcription machinery switches from initiation to elongation mode. FEBS Lett 564: 41-46.

Bierhoff H, Dundr M, Michels AA, Grummt I. 2008. Phosphorylation by casein kinase 2 facilitates rRNA gene transcription by promoting dissociation of TIF-IA from elongating RNA polymerase I. Mol Cell Biol 28: 4988-4998.

Blanc E, Roversi P, Vonrhein C, Flensburg C, Lea SM, and Bricogne G. 2004. Refinement of severely incomplete structures with maximum likelihood in BUSTER-TNT. Acta Crystallogr D Biol Crystallogr 60: 2210-2221.

Bodem J, Dobreva G, Hoffmann-Rohrer U, Iben S, Zentgraf $H$, Delius H, Vingron M, Grummt I. 2000. TIF-IA, the factor mediating growth-dependent control of ribosomal RNA synthesis, is the mammalian homolog of yeast Rrn3p. EMBO Rep 1: 171-175.

Bordi L, Cioci F, Camilloni G. 2001. In vivo binding and hierarchy of assembly of the yeast RNA polymerase I transcription factors. Mol Biol Cell 12: 753-760. 
Cavanaugh AH, Hirschler-Laszkiewicz I, Hu Q, Dundr M, Smink T, Misteli T, Rothblum LI. 2002. Rrn3 phosphorylation is a regulatory checkpoint for ribosome biogenesis. J Biol Chem 277: 27423-27432.

Cavanaugh AH, Evans A, Rothblum LI. 2008. Mammalian Rrn3 is required for the formation of a transcription competent preinitiation complex containing RNA polymerase I. Gene Expr 14: 131-147.

Chen HT, Hahn S. 2003. Binding of TFIIB to RNA polymerase II: mapping the binding site for the TFIIB zinc ribbon domain within the preinitiation complex. Mol Cell 12: 437-447.

Chen HT, Hahn S. 2004. Mapping the location of TFIIB within the RNA polymerase II transcription preinitiation complex: a model for the structure of the PIC. Cell 119: 169-180.

Chen ZA, Jawhari A, Fischer L, Buchen C, Tahir S, Kamenski T, Rasmussen M, Lariviere L, Bukowski-Wills JC, Nilges M, et al. 2010. Architecture of the RNA polymerase II-TFIIF complex revealed by cross-linking and mass spectrometry. EMBO J 29: 717-726.

Cingolani G, Petosa C, Weis K, Muller CW. 1999. Structure of importin- $\beta$ bound to the IBB domain of importin- $\alpha$. Nature 399: 221-229.

Claypool JA, French SL, Johzuka K, Eliason K, Vu L, Dodd JA, Beyer AL, Nomura M. 2004. Tor pathway regulates Rrn3pdependent recruitment of yeast RNA polymerase I to the promoter but does not participate in alteration of the number of active genes. Mol Biol Cell 15: 946-956.

Conti E, Kuriyan J. 2000. Crystallographic analysis of the specific yet versatile recognition of distinct nuclear localization signals by karyopherin $\alpha$. Structure 8: 329-338.

Cowtan K. 2006. The Buccaneer software for automated model building. 1. Tracing protein chains. Acta Crystallogr D Biol Crystallogr 62: 1002-1011.

Cramer P, Armache KJ, Baumli S, Benkert S, Brueckner F, Buchen C, Damsma GE, Dengl S, Geiger SR, Jasiak AJ, et al. 2008. Structure of eukaryotic RNA polymerases. Annu Rev Biophys 37: 337-352.

de La Fortelle E, Bricogne G. 1997. Maximum-likelihood heavyatom parameter refinement for multiple isomorphous replacement and multiwavelength anomalous diffraction methods. Methods Enzymol 276: 472-494.

Drygin D, Rice WG, Grummt I. 2010. The RNA polymerase I transcription machinery: an emerging target for the treatment of cancer. Annu Rev Pharmacol Toxicol 50: 131-156.

Emsley P, Cowtan K. 2004. Coot: model-building tools for molecular graphics. Acta Crystallogr D Biol Crystallogr 60: 2126-2132.

Eswar N, Eramian D, Webb B, Shen MY, Sali A. 2008. Protein structure modeling with MODELLER. Methods Mol Biol 426: 145-159.

Fan X, Lamarre-Vincent N, Wang Q, Struhl K. 2008. Extensive chromatin fragmentation improves enrichment of protein binding sites in chromatin immunoprecipitation experiments. Nucleic Acids Res 36: e125. doi: 10.1093/nar/qkn535.

Fath S, Milkereit P, Peyroche G, Riva M, Carles C, Tschochner H. 2001. Differential roles of phosphorylation in the formation of transcriptional active RNA polymerase I. Proc Natl Acad Sci 98: 14334-14339.

Geiger SR, Lorenzen K, Schreieck A, Hanecker P, Kostrewa D, Heck AJ, Cramer P. 2010. RNA polymerase I contains a TFIIF-related DNA-binding subcomplex. Mol Cell 39: 583-594.

Gerber J, Reiter A, Steinbauer R, Jakob S, Kuhn CD, Cramer P, Griesenbeck J, Milkereit P, Tschochner H. 2008. Site specific phosphorylation of yeast RNA polymerase I. Nucleic Acids Res 36: 793-802.
Gouet P, Courcelle E, Stuart DI, Metoz F. 1999. ESPript: analysis of multiple sequence alignments in PostScript. Bioinformatics 15: 305-308.

Grummt I, Voit R. 2010. Linking rDNA transcription to the cellular energy supply. Cell Cycle 9: 225-226.

Heck AJ. 2008. Native mass spectrometry: a bridge between interactomics and structural biology. Nat Methods 5: 927-933.

Hoppe S, Bierhoff H, Cado I, Weber A, Tiebe M, Grummt I, Voit R. 2009. AMP-activated protein kinase adapts rRNA synthesis to cellular energy supply. Proc Natl Acad Sci 106: 1778117786.

Huet J, Dezelee S, Iborra F, Buhler JM, Sentenac A, Fromageot P. 1976. Further characterization of yeast RNA polymerases. Effect of subunits removal. Biochimie 58: 71-80.

Imazawa $\mathrm{Y}$, Hisatake $\mathrm{K}$, Mitsuzawa $\mathrm{H}$, Matsumoto $\mathrm{M}$, Tsukui $\mathrm{T}$, Nakagawa K, Nakadai T, Shimada M, Ishihama A, Nogi Y. 2005. The fission yeast protein Kerlp is an ortholog of RNA polymerase I subunit A14 in Saccharomyces cerevisiae and is required for stable association of Rrn3p and RPA21 in RNA polymerase I. J Biol Chem 280: 11467-11474.

Jasiak AJ, Armache KJ, Martens B, Jansen RP, Cramer P. 2006. Structural biology of RNA polymerase III: subcomplex C17/ $25 \mathrm{X}$-ray structure and 11 subunit enzyme model. Mol Cell 23: $71-81$.

Kabsch W. 1993. Automatic processing of rotation diffraction data from crystals of initially unknown symmetry and cell constants. J Appl Crystallogr 26: 795-800.

Kassavetis GA, Prakash P, Shim E. 2010. The C53/C37 subcomplex of RNA polymerase III lies near the active site and participates in promoter opening. J Biol Chem 285: 2695-2706.

Keener J, Josaitis CA, Dodd JA, Nomura M. 1998. Reconstitution of yeast RNA polymerase I transcription in vitro from purified components. TATA-binding protein is not required for basal transcription. J Biol Chem 273: 33795-33802.

Knutson BA, Hahn S. 2011. Yeast Rrn7 and human TAF1B are TFIIB-related RNA polymerase I general transcription factors. Science (in press).

Konarev PV, Petoukhov MV, Volkov VV, Svergun DI. 2006. ATSAS 2.1, a program package for small-angle scattering data analysis. J Appl Crystallogr 39: 277-286.

Kosa PF, Ghosh G, DeDecker BS, Sigler PB. 1997. The 2.1-A crystal structure of an archaeal preinitiation complex: TATA-box-binding protein/transcription factor (II)B core/ TATA-box. Proc Natl Acad Sci 94: 6042-6047.

Kostrewa D, Zeller ME, Armache KJ, Seizl M, Leike K, Thomm M, Cramer P. 2009. RNA polymerase II-TFIIB structure and mechanism of transcription initiation. Nature 462: 323-330.

Kuhn CD, Geiger SR, Baumli S, Gartmann M, Gerber J, Jennebach S, Mielke T, Tschochner H, Beckmann R, Cramer P. 2007. Functional architecture of RNA polymerase I. Cell 131: $1260-1272$.

Laferte A, Favry E, Sentenac A, Riva M, Carles C, Chedin S. 2006. The transcriptional activity of RNA polymerase $I$ is a key determinant for the level of all ribosome components. Genes Dev 20: 2030-2040.

Lalo D, Steffan JS, Dodd JA, Nomura M. 1996. RRN11 encodes the third subunit of the complex containing Rrn6p and Rrn7p that is essential for the initiation of rDNA transcription by yeast RNA polymerase I. J Biol Chem 271: 21062-21067.

Larkin MA, Blackshields G, Brown NP, Chenna R, McGettigan PA, McWilliam H, Valentin F, Wallace IM, Wilm A, Lopez R, et al. 2007. Clustal $\mathrm{W}$ and Clustal $\mathrm{X}$ version 2.0. Bioinformatics 23: 2947-2948.

Lefevre S, Dumay-Odelot H, El-Ayoubi L, Budd A, Legrand P, Pinaud N, Teichmann M, Fribourg S. 2011. Structure-function analysis of hRPC62 provides insights into RNA poly- 
merase III transcription initiation. Nat Struct Mol Biol 18: 352-358.

Leitner A, Walzthoeni T, Kahraman A, Herzog F, Rinner O, Beck M, Aebersold R. 2010. Probing native protein structures by chemical cross-linking, mass spectrometry, and bioinformatics. Mol Cell Proteomics 9: 1634-1649.

Liu X, Bushnell DA, Wang D, Calero G, Kornberg RD. 2010. Structure of an RNA polymerase II-TFIIB complex and the transcription initiation mechanism. Science 327: 206-209.

Lorenzen K, Vannini A, Cramer P, Heck AJ. 2007. Structural biology of RNA polymerase III: mass spectrometry elucidates subcomplex architecture. Structure 15: 1237-1245.

Mayer C, Zhao J, Yuan X, Grummt I. 2004. mTOR-dependent activation of the transcription factor TIF-IA links rRNA synthesis to nutrient availability. Genes Dev 18: 423-434.

Mayer C, Bierhoff H, Grummt I. 2005. The nucleolus as a stress sensor: JNK2 inactivates the transcription factor TIF-IA and down-regulates rRNA synthesis. Genes Dev 19: 933-941.

Milkereit P, Tschochner H. 1998. A specialized form of RNA polymerase I, essential for initiation and growth-dependent regulation of rRNA synthesis, is disrupted during transcription. EMBO J 17: 3692-3703.

Miller G, Panov KI, Friedrich JK, Trinkle-Mulcahy L, Lamond AI, Zomerdijk JC. 2001. hRRN3 is essential in the SL1mediated recruitment of RNA Polymerase I to rRNA gene promoters. EMBO J 20: 1373-1382.

Moorefield B, Greene EA, Reeder RH. 2000. RNA polymerase I transcription factor Rrn3 is functionally conserved between yeast and human. Proc Natl Acad Sci 97: 4724-4729.

Moss T, Langlois F, Gagnon-Kugler T, Stefanovsky V. 2007. A housekeeper with power of attorney: the rRNA genes in ribosome biogenesis. Cell Mol Life Sci 64: 29-49.

Naidu S, Friedrich JK, Russell J, Zomerdijk JCBM. 2011. TAF1B is a TFIIB-like component of the basal transcription machinery for RNA polymerase I. Science (in press).

Panova TB, Panov KI, Russell J, Zomerdijk JC. 2006. Casein kinase 2 associates with initiation-competent RNA polymerase I and has multiple roles in ribosomal DNA transcription. Mol Cell Biol 26: 5957-5968.

Pape T, Schneider TR. 2004. HKL2MAP: a graphical user interface for phasing with SHELX programs. Acta Crystallogr D Biol Crystallogr 37: 843-844.

Peyroche G, Milkereit P, Bischler N, Tschochner H, Schultz P, Sentenac A, Carles C, Riva M. 2000. The recruitment of RNA polymerase I on rDNA is mediated by the interaction of the A43 subunit with Rrn3. EMBO J 19: 5473-5482.

Philimonenko VV, Zhao J, Iben S, Dingova H, Kysela K, Kahle M, Zentgraf H, Hofmann WA, de Lanerolle P, Hozak P, et al. 2004. Nuclear actin and myosin I are required for RNA polymerase I transcription. Nat Cell Biol 6: 1165-1172.

Philippi A, Steinbauer R, Reiter A, Fath S, Leger-Silvestre I, Milkereit P, Griesenbeck J, Tschochner H. 2010. TOR-dependent reduction in the expression level of Rrn3p lowers the activity of the yeast RNA Pol I machinery, but does not account for the strong inhibition of rRNA production. Nucleic Acids Res 38: 5315-5326.

Putnam CD, Hammel M, Hura GL, Tainer JA. 2007. X-ray solution scattering (SAXS) combined with crystallography and computation: defining accurate macromolecular structures, conformations and assemblies in solution. $Q R e v$ Biophys 40: 191-285.

Rinner O, Seebacher J, Walzthoeni T, Mueller LN, Beck M, Schmidt A, Mueller M, Aebersold R. 2008. Identification of cross-linked peptides from large sequence databases. Nat Methods 5: 315-318.
Schlosser A, Bodem J, Bossemeyer D, Grummt I, Lehmann WD. 2002. Identification of protein phosphorylation sites by combination of elastase digestion, immobilized metal affinity chromatography, and quadrupole-time of flight tandem mass spectrometry. Proteomics 2: 911-918.

Schnapp A, Grummt I. 1991. Transcription complex formation at the mouse rDNA promoter involves the stepwise association of four transcription factors and RNA polymerase I. J Biol Chem 266: 24588-24595.

Schnapp A, Schnapp G, Erny B, Grummt I. 1993. Function of the growth-regulated transcription initiation factor TIF-IA in initiation complex formation at the murine ribosomal gene promoter. Mol Cell Biol 13: 6723-6732.

Schneider T.R. and Sheldrick G.M. 2002. Substructure solution with SHELXD. Acta Crystallogr D Biol Crystallogr 58: 1772-1779.

Soding I, Biegert A, and Lupas A.N. 2005. The HHpred interactive server for protein homology detection and structure prediction. Nucleic Acids Res 33: W244-W248. doi: 10.1093/ nar/gki408.

Soutourina J, Wydau S, Ambroise Y, Boschiero C, Werner M. 2011. Direct interaction of RNA polymerase II and mediator required for transcription in vivo. Science 331: 1451-1454.

Svergun D, Barberato C, Koch MHI. 1995. CRYSOL—a program to evaluate X-ray solution scattering of biological macromolecules from atomic coordinates. J Appl Crystallogr 28: 768-773.

Takagi Y, Calero G, Komori H, Brown JA, Ehrensberger AH, Hudmon A, Asturias F, Kornberg RD. 2006. Head module control of mediator interactions. Mol Cell 23: 355-364.

Teichmann M, Wang Z, Roeder RG. 2000. A stable complex of a novel transcription factor IIB-related factor, human TFIIIB50, and associated proteins mediate selective transcription by RNA polymerase III of genes with upstream promoter elements. Proc Natl Acad Sci 97: 14200-14205.

Tsai FT, Sigler PB. 2000. Structural basis of preinitiation complex assembly on human pol II promoters. EMBO J 19: 25-36.

van den Heuvel RH, van Duijn E, Mazon H, Synowsky SA, Lorenzen K, Versluis C, Brouns SJ, Langridge D, van der Oost J, Hoyes J, et al. 2006. Improving the performance of a quadrupole time-of-flight instrument for macromolecular mass spectrometry. Anal Chem 78: 7473-7483.

Vannini A, Ringel R, Kusser AG, Berninghausen O, Kassavetis GA, Cramer P. 2010. Molecular basis of RNA polymerase III transcription repression by Maf1. Cell 143: 59-70.

Volkov VV, Svergun DI. 2003. Uniqueness of ab initio shape determination in small-angle scattering. I Appl Crystallogr 36: $860-864$.

Wang Z, Roeder RG. 1995. Structure and function of a human transcription factor TFIIIB subunit that is evolutionarily conserved and contains both TFIIB- and high-mobility-group protein 2-related domains. Proc Natl Acad Sci 92: 7026-7030.

Warner JR. 1999. The economics of ribosome biosynthesis in yeast. Trends Biochem Sci 24: 437-440.

Wriggers W, Chacon P. 2001. Using Situs for the registration of protein structures with low-resolution bead models from X-ray solution scattering. I Appl Crystallogr 34: 773-776.

Yamamoto RT, Nogi Y, Dodd JA, Nomura M. 1996. RRN3 gene of Saccharomyces cerevisiae encodes an essential RNA polymerase I transcription factor which interacts with the polymerase independently of DNA template. EMBO J 15: 3964-3973.

Zhao J, Yuan X, Frodin M, Grummt I. 2003. ERK-dependent phosphorylation of the transcription initiation factor TIF-IA is required for RNA polymerase I transcription and cell growth. Mol Cell 11: 405-413. 


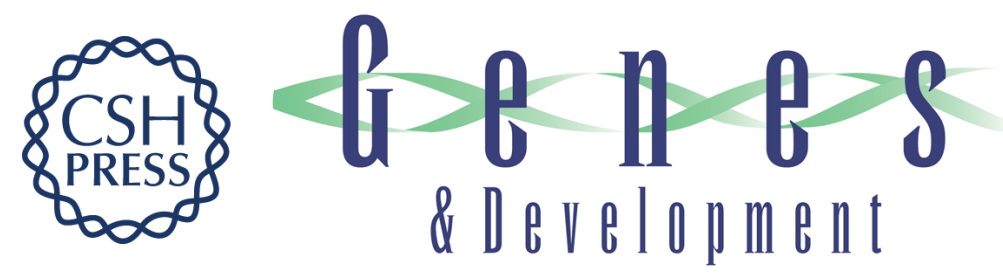

\section{Molecular basis of Rrn3-regulated RNA polymerase I initiation and cell growth}

Claudia Blattner, Stefan Jennebach, Franz Herzog, et al.

Genes Dev. 2011, 25: originally published online September 22, 2011

Access the most recent version at doi:10.1101/gad.17363311

$\begin{array}{ll}\text { References } & \begin{array}{l}\text { This article cites } 81 \text { articles, } 33 \text { of which can be accessed free at: } \\ \text { http://genesdev.cshlp.org/content/25/19/2093.full.html\#ref-list-1 }\end{array}\end{array}$

License

Email Alerting

Receive free email alerts when new articles cite this article - sign up in the box at the top Service right corner of the article or click here.

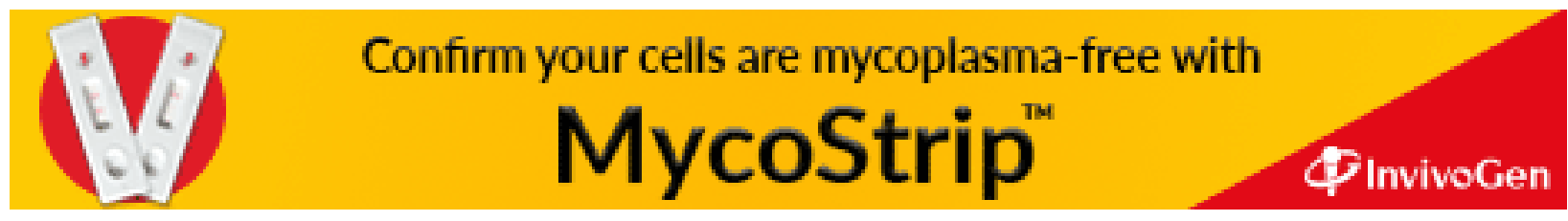

